\title{
SOBRE UMA METODOLOGIA NIETZSCHIANA PARA O ENSINO MÉDIO: RESULTADOS DE PESQUISA
}

\author{
Antônio Batista Soares Júnior ${ }^{1}$ \\ Marcos de Camargo Von Zuben ${ }^{2}$
}

\section{Resumo:}

Este artigo tem como objetivo apresentar os resultados de pesquisa sobre proposta metodológica de ensino de filosofia para o nível médio. Para tanto, tem como referência principal o pensamento educacional de Friedrich Nietzsche, mais especificamente dois movimentos filosóficos nietzschianos: o "tornar-se o que se é", o qual corresponde a uma necessária genealogia de si no processo de educação filosófica, e o que se liga ao tema da autossuperação, à afirmação de uma singularidade criativa de si como experiência filosófica por excelência. Desse modo, procura-se discutir como esses dois movimentos podem se constituir em práticas de ensino de filosofia e como podem ser apreendidos como referências para se pensar as melhores estratégias metodológicas para o ensino de filosofia. Trata-se, assim, de entender a dinâmica inerente à aprendizagem filosófica como ponto de partida para o estabelecimento de modos mais efetivos de ensinar filosofia aos estudantes do ensino médio. Apresentamse, neste artigo, as referências filosóficas, a descrição da metodologia e das atividades realizadas com os estudantes. Ao final, consta a avaliação do trabalho realizado. Concluiu-se que a metodologia elaborada e aplicada nas aulas de filosofia se mostrou apropriada aos objetivos visados.

Palavras-chave: Nietzsche. Metodologia. Ensino médio. Prática filosófica.

\section{ON A NIETZSCHIAN METHODOLOGY FOR HIGH SCHOOL: RESEARCH RESULTS}

\begin{abstract}
:
This article aims to present the results of the research on a methodological proposal for teaching philosophy at the high school. To do so, it has Friedrich Nietzsche's educational thought as its main reference, more specifically two Nietzschean philosophical movements: "becoming what one is", which corresponds to a necessary genealogy of the self in the process of philosophical education, and what it is linked to the theme of self-overcoming, to the affirmation of a creative singularity of oneself as a philosophical experience par excellence. In this way, we seek to discuss how these two movements can be constituted in practices of teaching philosophy and how they can be apprehended as references to think of as the best methodologies for teaching philosophy. It is, therefore, about understanding the dynamics inherent to philosophical learning as a starting point for establishing more effective ways of using philosophy for high school students. This article presents, as philosophical references, the description of the methodology and the activities carried out with the students. At the end, there is an evaluation of the work done. It was concluded that the methodology developed and applied in the philosophy classes is appropriate to the objectives pursued.
\end{abstract}

Keywords: Nietzsche. Methodology. High school. Philosophical practice.

\footnotetext{
${ }^{1}$ Especialista em Ensino de Filosofia no Ensino Médio pela Universidade Federal do Rio Grande do Norte e Mestre em Filosofia pelo Programa de Mestrado Profissional em Filosofia - PROF-FILO da Universidade do Estado do Rio Grande do Norte. Professor de Filosofa da Escola Cooperativa de Parelhas - COOEPAR-RN. (E-mail: jrbatistajr@hotmail.com).

${ }^{2}$ Doutor em Filosofia pela Unicamp. Professor do Departamento de Filosofia, do Programa de Pós-graduação em Ciências Sociais e Humanas e do Programa de Pós-graduação Profissional em Filosofia da Universidade do Estado do Rio Grande do Norte/UERN. (E-mail: zuben@uol.com.br).
} 


\section{Introdução}

Este artigo tem como objetivo apresentar, sumariamente, os resultados de pesquisa realizada no mestrado profissional em filosofia ${ }^{3}$ que visou a elaboração, aplicação e avaliação de proposta metodológica de ensino de filosofia no nível médio tomando como referência principal o pensamento educacional de Friedrich Nietzsche. Procura-se com esta pesquisa aperfeiçoar as metodologias de ensino de filosofia no nível médio, de modo a tornar a prática filosófica mais significativa aos estudantes e mais efetiva do ponto de vista filosófico, desafio por demais presente quando, por um lado, prevalece no ensino médio a concepção técnicocientífica de aprendizagem e, por outro, quando constata-se a ainda incipiente experiência da prática filosófica no ensino médio, não obstante o que já se pôde acumular de conhecimentos e troca de experiências sobre o ensino de filosofia desde o retorno da sua obrigatoriedade há doze anos no Brasil.

O que se apresenta dos resultados da investigação se referem a dois momentos. No primeiro momento, apresentam-se e discutem-se dois movimentos filosóficos presentes em Nietzsche considerados mais importantes para pensar a educação e, em especial, o ensino de filosofia. O primeiro movimento é aquele do "tornar-se o que se é", do chegar a ser o que se é, lema de Píndaro levado ao superlativo na filosofia de Nietzsche. A esse movimento corresponde o que seria uma necessária genealogia de si no processo de educação filosófica. O segundo movimento, que se segue existencialmente ao anterior, liga-se ao tema do além-homem (übermensch) nietzschiano, é aquele em direção à autossuperação, a afirmação de uma singularidade criativa de si como experiência filosófica por excelência. Em relação a esses dois movimentos se procurou investigar em que medida eles podem ser tomados como referência para a constituição de uma prática filosófica de ensino de filosofia no nível médio. No segundo momento, é apresentada a atividade de intervenção em que se procurou aplicar a proposta metodológica elaborada e a avaliação dos resultados da pesquisa.

O que é de interesse nesta investigação não é tanto a discussão sobre todos os aspectos implicados aos problemas da educação presentes no pensamento do filósofo alemão, mas antes a apreensão do que se nomeia os movimentos da prática filosófica que possam constituir-se como referências para se pensar as melhores estratégias metodológicas para o ensino de filosofia. Trata-se, assim, de compreender a dinâmica inerente à aprendizagem

\footnotetext{
${ }^{3}$ SOARES JÚNIOR, Antônio Batista. Nietzsche e o ensino de filosofia: uma metodologia para o ensino médio.
} Dissertação (Mestrado Profissional em Filosofia) - Universidade do Estado do Rio Grande do Norte, 2019. 
filosófica como ponto de ancoragem para o estabelecimento de modos mais efetivos de ensinar filosofia aos estudantes do ensino médio.

\section{Diagnóstico do presente para "tornar-se o que se é" no processo de educação filosófica}

O "tornar-se o que se é", como primeiro movimento, perpassa o caráter sempre genealógico da investigação filosófica. Em A Gaia Ciência no aforismo 270 Nietzsche (2001, p. 186) afirma: “O que diz sua consciência? - 'Torne-se aquilo que você é”. É válido ressaltar que essa frase é, antes de tudo, lema de Píndaro, porém ganha uma espécie de ressignificação na filosofia de Nietzsche quando este atribui à referida frase uma interpretação que a eleva a um sentido propriamente criativo, o que possibilita pensar o aspecto da formação.

Segundo Foucault (1994, p. 606), a partir de Nietzsche a filosofia tem por tarefa "diagnosticar, realizar um diagnóstico do presente, dizer o que somos hoje e o que significa hoje dizer isto que nós somos". Este trabalho de realizar o diagnóstico da atualidade passa, necessariamente, para Nietzsche (1998, p. 60), pela realização de um trabalho genealógico em relação aos conceitos, valores e modos de vida.

É a partir desse diagnóstico, dessa genealogia de si, que se começa a articular o primeiro movimento - tornar-se o que se é - como impulso do vir a ser, que se põe como ponto de partida para a formação filosófica. Esse processo que intervém a um diagnóstico de si, perpassa também por um diagnóstico da cultura já que "Nietzsche, também se insere, vigorosamente, na crítica da cultura e das instituições de cultura de seu tempo" (LARROSA, 2009, p. 44). Nessa perspectiva, esse movimento, com vistas a um caráter formativo na educação filosófica, é um convite nietzschiano ao sujeito para o experimento de si próprio na esfera do "formar a si próprio", do "fazer-se a si próprio", "cultivar a si próprio".

A autocompreensão reflexiva de si como resultado, como diagnóstico de si traz à tona o que se é, e o "tornar-se" é o que faz, o que move, o que transforma o sujeito, o que o impulsiona a tornar-se cada vez mais. De modo que [...] "Só quando uma vontade puramente afirmativa atravessa 'o que se é', o homem se converte em 'o que é' (LARROSA, 2009, p. 61). Esse movimento no processo de educação filosófica é o que impulsiona a formação da singularidade do sujeito na medida em que este torna-se, assim, criador de sua própria forma.

Dessa maneira, o convite nietzschiano ao sujeito para tornar-se o que se é traz consigo o caráter de ser um sujeito diferente, não pertencente à massa. Na III Consideração Intempestiva: Schopenhauer Educador o filósofo alemão destaca o caráter de libertação do

\begin{tabular}{|c|c|c|c|c|}
\hline Qevista Dialectus & Ano 9 & n. 20 & Outubro - Novembro 2020 & p. 188 - 208 \\
\hline
\end{tabular}


sujeito no seu trajeto educacional no que se refere a este não querer pertencer à massa, e isso se expressa quando o mesmo afirma:

\begin{abstract}
O homem que não quer pertencer à massa só precisa deixar de ser indulgente para consigo mesmo; que ele siga a sua consciência que lhe grita: "Sê tu mesmo! Tu não és isto que agora fazes, pensas e desejas". [...] enquanto permanecer nas cadeias da opinião corrente e do medo. E como pode ser desesperada e desprovida de sentido a vida sem esta libertação! (NIETZSCHE, 2003, p. 139).
\end{abstract}

Ora, esse sujeito obedece à sua consciência e diz para si que não pode se acomodar com sua condição, propondo-se a si mesmo um tornar-se, ser ele mesmo, buscando assim, ser diferente e não pertencer à massa. Nesse sentido, o filósofo se engaja em seu projeto de elevação da cultura, mas de uma cultura superior, uma cultura de indivíduos selecionados, pois: “[...] não é a cultura da massa que deve ser a nossa finalidade, mas a cultura de indivíduos selecionados, munidos das armas necessárias para a realização das grandes obras que ficarão" (NIETZSCHE, 2003, p. 90). Contudo, Nietzsche pressupõe que se já é sempre uma consciência gregária e massificada como ser social e cultural, e que assim se deve, por um movimento genealógico em relação aos próprios valores, por uma genealogia de si, tomar distância daquilo que nos torna a todos comuns e iguais, da consciência comum e pacificada da coletividade, para deixar emergir aquilo que em cada um é singular e próprio.

Desse modo, pode-se tomar o "tornar-se o que se é" como forma de vida, uma vez que em A Gaia Ciência, especificamente no final do parágrafo 299, intitulado "O que devemos aprender com os artistas", Nietzsche (2001, p. 202) explica: [...] "Pois neles esta sutil capacidade termina, normalmente, onde termina a arte e começa a vida; nós, no entanto, queremos ser os poetas-autores de nossas vidas, principiando pelas coisas mínimas e cotidianas". Sobretudo, o convite nietzschiano ao sujeito para tornar-se o que se é, propõe a este ser autor de si, criador de si e da própria vida tendo em vista um reconhecimento de si em direção a um pleno e constante tornar-se, pois o sujeito é este que somente ele é quem pode construir-se no fluxo da vida, e claramente Nietzsche afirma (2003, p. 140-141):

Ninguém pode construir no teu lugar a ponte que te seria preciso tu mesmo transpor no fluxo da vida - ninguém, exceto tu. Certamente, existem as veredas e as pontes e os semideuses inumeráveis que se oferecerão para te levar para o outro lado do rio, mas somente na medida em que te vendesses inteiramente: tu te colocarias como penhor e te perderias. Há no mundo um único caminho sobre o qual ninguém, exceto tu, poderia trilhar. Para onde leva ele? Não perguntes nada, deves seguir este caminho.

Assim, no processo do "torna-se o que se é” o sujeito precisa encontrar o seu próprio caminho. É caminho único que somente o sujeito - ele mesmo - pode se direcionar a um tornar-

\begin{tabular}{|c|c|c|c|c|}
\hline Qevista Dialectus & Ano 9 & n. 20 & Outubro - Novembro 2020 & p. 188 - 208 \\
\hline
\end{tabular}


se. E nessa perspectiva nietzschiana a invenção tem um papel crucial para o tornar-se do sujeito, pois como diz Larrosa (2009, p. 45): [...] "isso que somos e que temos de chegar a ser está claramente do lado a invenção. O homem é um animal de invenção, e as diferentes formas de consciência não são senão produtos dessa função inventiva, dessa capacidade de invenção".

O sentido do tornar-se o que se é se delineia na filosofia nietzschiana sob a perspectiva do sujeito que se cria, de um "eu inventor artista de si que se inventa", ou seja:

[...] O eu que importa é aquele que há sempre além daquele que se toma habitualmente por sujeito: não está por descobrir, mas por inventar; não por realizar, mas por conquistar; não por explorar, mas por criar da mesma maneira que um artista cria uma obra. Para chegar ao que se é, tem que se ser artista de si mesmo. (LARROSA, 2009, p. 64-65)

Ser artista de si mesmo é a proposta nietzschiana que vai ao encontro da singularidade do sujeito que concebe a ideia criativa de si em um pleno inventar, em um pleno "tornar-se". Assim, entende-se que o lema "tornar-se o que se é" representa um movimento que perpassa a singularidade do sujeito e que por isso está intimamente ligado ao processo de aprendizagem filosófica como um movimento necessário à prática filosófica.

\section{Filosofia como invenção de si: a definição de vida como vontade de potência e a vontade criadora como autossuperação}

Nietzsche propõe a definição de "vida" como "vontade de potência" e o termo "vontade criadora" na perspectiva da criação de si, partindo da análise do campo da moral, para pensar tais conceitos na esfera da elevação do homem, e, ainda, como essas noções podem se tornar necessárias no processo educacional filosófico na vida dos educandos, trazendo para discussão as ideias de "autossuperação" e "além do homem".

Dias (2011, p. 33), ao interpretar as ideias do filósofo, revela o que para ele significa ser vida assim como também demonstra as indagações dele acerca das leis morais, afirmando que "Para Nietzsche, pensar, sentir, avaliar são sempre sintomas das formas de vida, de sua plenitude, de sua potencialidade ou de suas obstruções, seus cansaços e empobrecimentos".

Assim, pensar, sentir e avaliar estão inclusos no caráter próprio da vida, são sintomas das formas de vida. Em suas indagações acerca da moral, o filósofo faz referência ao fato de tais leis morais resultarem em dominação à vida, ou seja, essas leis que damos a nós próprios não nos permitem viver intensamente, não nos permitem expandir nossa potencialidade. Com efeito, ao dizer que as leis morais resultam em dominação, Nietzsche

\begin{tabular}{|c|c|c|c|c|}
\hline Rovista Dialectus & Ano 9 & n. 20 & Outubro - Novembro 2020 & p. $188-208$ \\
\hline
\end{tabular}


procura, a nosso ver, dizer também o que pensa ser "vida" em contraposição àquilo que é posto como dominação à vida. Sobretudo, o conceito de vontade de potência é de grande importância na filosofia de Nietzsche, pois para ele a vida é "vontade de potência", mas o que isso significa? Segundo Dias (2011, p. 34),

[...] é na seção intitulada 'Da superação de si' que o filósofo equipara o conceito de vontade de potência ao de vida. Nesse momento, caracteriza a vontade de potência como vontade orgânica; ela é própria não unicamente do homem, mas de todo ser vivo. [...] A vida, como vontade de potência, como eterno superar-se, é, antes de tudo, atividade criadora e como tal é alguma coisa que quer expandir sua força, crescer, gerar mais vida.

Desse modo, o filósofo conceitua vida como vontade de potência na medida em que é "atividade criadora"; é atividade criadora na medida em que quer gerar mais vida, um eterno superar-se. Vontade de potência está estritamente ligada à vontade que, por assim dizer, quer estar em constante crescimento, querendo de fato expandir sua força. A vontade de potência é também caracterizada como vontade orgânica, porém, esta existe em todos os seres vivos e não apenas no homem. A esse respeito Dias (2011, p. 43) explica que a vontade de potência é o "mais forte de todos os impulsos, aquele que até hoje dirige toda evolução orgânica. Os instintos, os impulsos, a atividade, a força são, em última instância, a linguagem particular da vontade de potência".

Para dar continuidade à discussão sobre vontade de potência como vida e para se entender o caráter desse termo como atividade criadora, faz-se necessário compreender que Nietzsche, além de ser um defensor da vida, é também um defensor da arte. Para ele, a arte é elemento que conduz à atividade criadora, que coloca o homem em um patamar de construir-se a si mesmo, e é a partir dessa perspectiva da arte que o filósofo deseja fazer uma conexão, uma interligação entre vida, pensamento e arte.

Mas o que o filósofo compreende por arte e o que ela tem a ver com a existência em seu sentido mais amplo em relação à vida? Com base na interpretação dos escritos nietzschianos, Dias (2011, p. 56) explica que "a arte é essencialmente afirmação, divinização da existência. Nietzsche valoriza os impulsos estéticos como condição de criação de novas condições de existência".

A arte está estritamente ligada à existência, pois a partir da arte e dos impulsos estéticos pode haver, para Nietzsche, criação de novas condições de existência, em outras palavras, novas formas de vida. Se em prol de outro mundo a tradição filosófica negou a vida em nome de valores superiores depositando uma crença na razão com base na metafísica, agora

\begin{tabular}{|c|c|c|c|c|}
\hline Qovista Dialectus & Ano 9 & n. 20 & Outubro - Novembro 2020 & p. $188-208$ \\
\hline
\end{tabular}


precisamos não mais negar a vida como fez a tradição, e sim afirmá-la. É com a "potência criadora" que se pode trazer isso à tona. A potência criadora e a arte são o que estimulam à vida, que a tornam possível. Desse modo, é por meio da arte que se pode afirmar a vida, dar propriamente sentido à existência.

Posto que arte é essencialmente afirmação, faz-se necessário compreender o termo "vontade de potência" como "atividade criadora". Os dois termos estão interligados ao conceito de "vida como vontade criadora". A vontade de potência como algo que quer crescer, gerar mais vida, é, portanto, vontade criadora. Criar é algo próprio da vida na medida em que possibilita novas formas de vida. Estas se efetivam quando a vontade criadora impulsiona o ato de criar fazendo com que possam estar em constante vir-a-ser, podendo, pois, gerar vontade de crescer cada vez mais. Entretanto, sobre a vontade criadora como algo que se relaciona com o devir, Dias (2011, p. 70) diz: A doutrina da vontade criadora, a vontade como força artística, tal como Nietzsche a
concebe, é uma nova maneira de pensar que se aplica ao devir. Não há começo, nem
ponto final; tudo está ainda por se fazer. E dizer que tudo está em mudança é dizer
que tudo está sujeito às leis da destruição. A realidade do devir, da mudança, é a única
realidade.

A possibilidade do criar como sendo algo próprio da vida se justifica justamente porque tudo está em plena mudança como também está para se fazer, uma vez que não há começo nem fim, e, desse modo, tudo está sujeito às leis da destruição. Logo, no criar também está incluso o destruir, mas este como possibilidade do vir-a-ser, e sendo assim, o devir é, por assim dizer, condição para que haja constante criação. Portanto, é nessa perspectiva que vontade de vir-a-ser, de crescer, significa atividade que produz constantemente a vida. Assim, vontade como força artística, na perspectiva nietzschiana, é vontade criadora na medida em que é atividade criadora. Sobretudo, a arte é o que estimula, é o estimulante que impulsiona a vida como vontade criadora.

Ora, o movimento do "tornar-se o que se é" e o movimento de "vontade de potência" como "vontade criadora" se configuram no âmbito da "autossuperação de si" na medida em que estão imersos na esfera da afirmação de uma singularidade criativa de si como experiência filosófica por excelência. O que se afirma nesse movimento positivo é a potência criativa de autossuperação, a afirmação do vir a ser próprio de cada um. O devir na perspectiva de um vir a ser, no sentido do criar a si mesmo, traz consigo a proposta de fazer com que as singularidades (os educandos) possam desenvolver suas potencialidades tendo em vista um superar-se, refletindo sobre sua vida como vontade criadora de si. Nesse ponto, a ideia de

\begin{tabular}{|c|c|c|c|c|}
\hline Qevista Dialeatus & Ano 9 & n. 20 & Outubro - Novembro 2020 & p. $188-208$ \\
\hline
\end{tabular}


autossuperação nietzschiana constitui-se como ancoragem necessária para pensar a aprendizagem filosófica, que estrutura esse segundo movimento inerente às práticas filosóficas.

Têm-se, assim, dois movimentos importantes para pensar o fazer filosófico: o diagnóstico de si e a superação de si ou autossuperação, movimentos que são um convite nietzschiano aos estudantes a conceber suas singularidades como potência criadora de si mesmo em direção a uma autossuperação de si mesmo. É um convite para que a experiência filosófica de si ultrapasse sua condição massificada em direção a novas formas de ser e de pensar.

\section{Metodologia de ensino das aulas de filosofia}

A proposta metodológica apresenta-se em quatro passos tendo como objetivo a ação didática filosófica. Os dois primeiros passos dizem respeito ao movimento genealógico. Os outros dois se referem ao movimento da autossuperação.

O primeiro movimento, da genealogia, tem implicada a tarefa de articular as condições didáticas para a realização da crítica da cultura em articulação com as teorias, conceitos e ideias filosóficas que de algum modo a sustentam ou dão sentido às práticas culturais vigentes dos estudantes. Assim, esse movimento se configura da seguinte forma:

$1^{\circ}$ passo: Exposição temática e problemática: consiste na exposição do tema filosófico em questão bem como na apresentação do problema social que envolve à temática, numa breve explicação e discussão do tema abordado.

$2^{\circ}$ passo: Investigação interpretativa conceitual: refere-se ao conhecimento a fundo da temática. Por meio dela, os alunos podem fazer leitura de texto (coletiva ou não), pesquisa sobre o tema e conceitos filosóficos em material didático (ou em dicionário de filosofia, etc.) assim como um estudo aprofundado do tema tendo em vista a compreensão dos conteúdos e conceitos da filosofia, a partir das orientações postas pelo professor.

A principal habilidade a ser exercitada nesse primeiro movimento genealógico é a leitura filosófica, tanto dos registros culturais provenientes de outras linguagens e meios de difusão quanto de textos propriamente filosóficos.

É nesse passo de investigação interpretativa conceitual que o professor pode impulsionar e incentivar os alunos a conhecer os conceitos filosóficos que permitem estabelecer uma relação com sua existência no intuito de que os estudantes possam exercitar o olhar filosófico sobre si e sobre os valores que estão penetrados também em sua cultura. 
O segundo movimento, da autossuperação de si, visa, por um lado, a ampliar a capacidade questionadora dos estudantes, e, por outro lado, a abrir a possibilidade de pensar diferentemente, de pensar pessoal e criativamente possíveis respostas às questões levantadas, de modo a exercitar a capacidade de pensamento crítico e autônomo por parte dos estudantes.

$1^{\circ}$ passo: Problematização argumentativa: consiste no levantamento de questões sobre o tema e criação de outros problemas dentro da temática, avaliando o porquê de os alunos terem criado determinada pergunta, e, assim, avaliando suas argumentações.

$2^{\circ}$ passo: Produção filosófica: diz respeito à produção filosófica por parte dos alunos. Seja por meio de produção textual, seja através de debates teóricos de conceitos, seminários avaliativos com explicação de conteúdos. Este segundo passo constitui-se na elaboração de um texto dissertativo pelos estudantes a partir da pergunta elaborada por cada um, assim como do olhar retrospectivo que cada estudante pode fazer em relação às suas primeiras opiniões ou impressões que possuía ao início do estudo do tema, de modo a lhe uma relação criativa com sua própria cultura e também consigo mesmo. Assim, a principal habilidade a ser exercitada é a escrita filosófica, a partir das fontes textuais utilizadas durante o estudo e nas explicações do professor durante as aulas, tendo em vista responder à pergunta selecionada, ou a uma pergunta que tenha a devida relação com o tema em questão e com problemas reais presentes na sociedade e em sua cultura. Essa dissertação filosófica almeja que os alunos façam conexões entre o conteúdo filosófico, sua existência, seus valores e os valores implícitos em sua cultura produzindo filosofia a partir de seu pensamento filosófico.

Vale ressaltar que os quatro passos metodológicos apresentados constituem uma possibilidade dentre outras de prática de ensino de filosofia no qual a metodologia poderá ser aplicada. Porém, outro aspecto importante a se destacar é que diante de uma grande abrangência de temas que compõem a filosofia na sua história, reafirma-se que nem todos os conteúdos filosóficos podem ser tratados por meio da metodologia proposta, necessitando de ajustes e adaptações em razão da peculiaridade da temática estudada.

\section{Da aplicação e avaliação da metodologia}

A discussão apresentada neste artigo diz respeito a aspectos que se referem à aplicação e à avaliação da metodologia tal qual foi criada no decorrer da pesquisa, baseando-se em apontamentos da filosofia de Nietzsche, que foram tomados como referência para a construção da metodologia desenvolvida. Também se direciona aos aspectos descritivos que

\begin{tabular}{|c|c|c|c|c|}
\hline Q Rovista Qialectus & Ano 9 & n. 20 & Outubro - Novembro 2020 & p. $188-208$ \\
\hline
\end{tabular}


correspondem às execuções metodológicas em sala de aula, uma vez que o trabalho de pesquisa se propôs a elaborar uma metodologia que possa ser considerada válida para o ensino médio, ser aplicada em aulas de filosofia e, em seguida, ser avaliada a fim de verificar sua validade, tendo como pretensão a melhoria de práticas de ensino de filosofia e, consequentemente, do ensino filosófico no nível médio.

A pesquisa foi realizada na Escola Cooperativa de Parelhas (COOEPAR), localizada na cidade de Parelhas-RN. A população estudada se constituiu de 21 alunos que integravam a turma da $2^{\text {a }}$ série do ensino médio, do turno matutino. A escolha dessa turma se justifica porque esses alunos estavam na $2^{\mathrm{a}}$ série do ensino médio e já tinham a base teórica filosófica da $1^{\text {a }}$ série, e, ainda, apresentavam mais interesse filosófico nas aulas de filosofia. Além disso, a maioria tinha, por assim dizer, disponibilidade em participar da pesquisa.

Essa $2^{\text {a }}$ série era composta por 16 estudantes do sexo feminino e 5 do sexo masculino, com faixa etária entre 16 a 19 anos de idade. Todos são da zona urbana. Assim, não houve dificuldade de os alunos terem acesso ao local de realização do estudo. Porém, só participaram da pesquisa os alunos que se voluntariaram e cujos responsáveis permitiram conscientemente a devida participação por meio da assinatura de um termo de autorização.

A pesquisa desenvolvida é de natureza qualitativa uma vez que possibilita ir a campo (sala de aula), intervir e avaliar aspectos sobre as perspectivas dos participantes que estão envolvidos como objeto de pesquisa, seus significados e suas múltiplas visões subjetivas, assim como propõe uma melhor visão, compreensão, análise e resolução do problema proposto no estudo (YIN, 2016).

Entender as perspectivas dos alunos pode contribuir para verificar os resultados da aplicação da proposta metodológica estudada, tendo em vista a compreensão e o discernimento das situações que são pertinentes para uma avaliação das perspectivas dos estudantes, como também traz, de maneira concreta, aspectos importantes para delinear experimentos metodológicos no ato da pesquisa.

A natureza da metodologia adotada foi a pesquisa-ação, a qual, segundo Thiollent (2008, p. 14), é “concebida e realizada em estreita associação com uma ação ou com a resolução de um problema coletivo no qual os pesquisadores e os participantes representativos da situação ou do problema estão envolvidos de modo cooperativo ou participativo".

A constituição de dados ocorreu a partir de observações das aulas por parte do pesquisador responsável; da aplicação de questionário com os alunos da $2^{\mathrm{a}}$ série do ensino

\begin{tabular}{|l|l|l|l|l|}
\hline Govista & Ano 9 & n. 20 & Outubro - Novembro 2020 & p. $188-208$ \\
\hline
\end{tabular}


médio; e de uma roda de conversa avaliativa realizada com os alunos gravada em áudio. Os procedimentos de avaliação dessa metodologia sucederam-se em quatro etapas, a saber:

$1^{\mathrm{a}}$ etapa: análise dos questionários respondidos pelos alunos;

$2^{\text {a }}$ etapa: relato e análise da roda de conversa avaliativa;

$3^{\text {a }}$ etapa: análise empírica, reflexiva e interpretativa como professor de filosofia participante da ação, de elaboração da metodologia, da sua execução e avaliação.

$4^{\mathrm{a}}$ etapa: identificação (diagnóstico) da validade da metodologia para aulas de filosofia no ensino médio.

Isso posto, a seguir descrevem-se as atividades desenvolvidas em sala de aula nos aspectos que dizem respeito à aplicação da metodologia nos quatro passos, de forma sequencial, em que ela se configura. É válido ainda ressaltar que os dois primeiros passos correspondem ao primeiro movimento genealógico. Por conseguinte, os dois últimos representam o segundo movimento que diz respeito à superação de si, quais sejam:

$1^{\circ}$ passo: exposição temática e problemática;

$2^{\circ}$ passo: investigação interpretativa conceitual;

$3^{\circ}$ passo: problematização argumentativa;

$4^{\mathrm{o}}$ passo: produção filosófica.

Desse modo, foram feitas três intervenções metodológicas (no total final de nove horas/aula) tendo como tema central "A metafísica", sendo que em cada execução metodológica foram trabalhados conteúdos diversos da metafísica, utilizando os quatro passos da metodologia supracitada. Cada intervenção corresponde a três horas/aula. Dessa forma, sucederam-se três execuções metodológicas na $2^{\mathrm{a}}$ série do ensino médio. Os conteúdos trabalhados são propostos pelo livro didático ${ }^{4}$ de ensino (Módulo volume 9 - ensino médio). O conteúdo trabalhado na primeira execução foi "Metafísica de Aristóteles", na segunda "Metafísica Medieval e Moderna" e na terceira "Crítica à Metafísica". Devido à extensão dessas três execuções, apresentam-se somente os passos da segunda, como exemplo, já que as outras duas seguiram a mesma metodologia.

O conteúdo abordado na segunda execução, como afirmado, foi a "Metafísica Medieval e Moderna". Na primeira aula, a partir do primeiro passo (exposição temática e problemática) apresentaram-se os temas com breves explicações do professor e algumas perguntas iniciais acerca do contexto histórico e filosófico da metafísica medieval falando sobre

${ }^{4} \mathrm{O}$ livro didático de ensino utilizado nas aulas foi proposto pelo Sistema Positivo de Ensino, sistema adotado pela escola (COOEPAR).

\begin{tabular}{|l|l|l|l|l|}
\hline Qonista & Ano 9 & n. 20 & Outubro - Novembro 2020 & p. $188-208$ \\
\hline
\end{tabular}


como surgiu a mesma partindo da metafísica cristã exemplificando que nesse período os temas de maior relevância eram Deus e a salvação da alma humana, afirmando que os filósofos problematizaram questões relativas aos domínios da fé e da razão, todavia, demonstrou-se as duas fases do pensamento filosófico da Idade Média: a Patrística e a Escolástica.

O professor introduziu logo em seguida o tema da metafísica moderna com explicações sucintas sobre o referido tema já que a atividade que viria logo após seria de grupo, uma vez que haveria mudança na dinâmica das atividades, porém respeitando os passos da metodologia. Dentro da metafísica moderna, o professor explicou brevemente que no século XVII as ciências experimentais atingiam um desenvolvimento notável e a filosofia já havia adquirido maior independência em relação à igreja e à religião, entretanto, a metafísica ainda considerava três tipos de substância em suas investigações sobre a realidade: substância infinita; substância pensante; e substância extensa. Contudo, as discussões filosóficas da Idade Moderna estavam voltadas para a questão propriamente do conhecimento que, por um lado, se centrava no conhecimento a partir da razão, e, por outro, na experiência. Perguntas foram levantadas em torno dos dois temas. No que se refere à metafísica medieval: o que é razão? O que entendemos por fé? Podemos provar a existência de Deus? No que concerne à metafísica moderna: o que é causa (causalidade)? O que é conhecer? É possível conhecermos todas as coisas? É possível conhecer os objetos em si mesmos? Todas essas questões foram levantadas no intuito de instigar os alunos e deixá-los inquietos para se envolverem com maior ênfase na atividade seguinte. Dessa forma cumpriu-se o primeiro passo metodológico.

Na mesma aula, seguindo o segundo passo (investigação interpretativa conceitual), foi direcionada pelo professor uma atividade de grupo avaliativa na qual a turma foi dividida em quatro grupos ( 3 grupos de 5 alunos e 1 grupo de 6 alunos). Os dois primeiros ficaram com o tema da metafísica medieval e os dois últimos com o da metafísica moderna. Todos os grupos iriam investigar os conceitos filosóficos no material didático presente. Enquanto acontecia esse momento de pesquisa, o professor fazia orientações nos grupos e tirava dúvidas sobre os temas e conceitos que não estavam sendo compreendidos pelos discentes. Essa atividade perdurou até o final dessa primeira aula.

Como não foi possível terminar a atividade nessa primeira aula, deu-se sua continuidade na segunda aula. Os grupos reuniram-se novamente e a partir das orientações do professor e da compreensão dos conceitos dos respectivos conteúdos que estavam sendo trabalhados, seguiu-se o terceiro passo metodológico (problematização argumentativa), a atividade proposta que se dirigiu a cada grupo era a de construir quatro questões (eles também

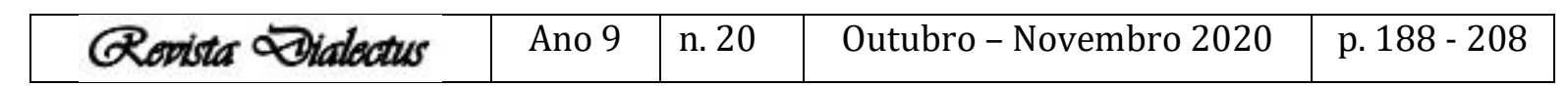


tinham de respondê-las) sobre seus temas e subtemas levando em consideração os conceitos filosóficos. Nesse momento, o professor atendia ao chamado dos grupos para sanar algumas dúvidas, verificava como as perguntas estavam sendo criadas, orientava e indicava os caminhos para melhorar as questões que haviam necessidade de serem reconstruídas, todavia, avaliavase ainda o porquê de os alunos terem criado determinadas questões.

Finalizado o terceiro passo, no quarto passo metodológico (produção filosófica) os discentes receberam a orientação de que cada grupo deveria apresentar na aula seguinte seu trabalho em forma de seminário para toda a turma de modo que explicassem seu conteúdo, apresentassem as questões que foram construídas e suas respostas, e, por fim, fizessem uma crítica sobre algum aspecto da metafísica (medieval/moderna) que na visão deles encontra-se presente na nossa cultura atual nos impedindo de pensar filosoficamente a realidade. Em seguida, foi orientado que eles escolhessem um modo criativo para apresentar o trabalho, seja por meio de cartolina com desenho crítico, poesia criada, charge, mapa mental, seja por meio de música, entre outros.

$\mathrm{Na}$ terceira aula, dando seguimento ao quarto passo da metodologia, foram apresentados todos os seminários, no tempo de dez minutos para cada grupo. Os grupos 1 e 2 abordaram os temas da metafísica medieval trazendo a discussão que integrava a Patrística e a Escolástica, o cristianismo e os elementos platônicos e neoplatônicos, as cinco vias de Tomás de Aquino utilizadas por ele para provar racionalmente a existência de Deus, e a querela dos universais. Os grupos 3 e 4 expuseram os temas da metafísica moderna apresentando o racionalismo nas ideias de René Descartes discutindo o método cartesiano a partir do racionalismo da dúvida metódica. Demonstraram o que foi a revolução copernicana, explicaram conceitos de Kant sobre os juízos analíticos, juízos sintéticos, juízos a priori e a posteriori, assim como as categorias do entendimento. Trouxeram ainda as ideias dos filósofos empiristas como David Hume discutindo a causalidade e John Locke na sua representação da mente humana como uma tábula rasa.

Todos os grupos apresentaram as questões construídas e as respectivas respostas, e, ao final, os participantes dos grupos em consenso realizaram uma crítica de modo criativo: o grupo 1 utilizou desenho; o grupo 2 usou charges; o grupo 3 fez um mapa mental de ideias e elaborou um cartaz no qual fez um trabalho de colagem de imagens referenciando a ciência na Idade Moderna e a ciência atual, seus avanços e problemas trazidos por seu rápido crescimento; o grupo 4 criou uma poesia criticando também os avanços científicos tecnológicos que fazem o ser humano deixar-se levar pela distração sem pensar filosoficamente sua realidade.

\begin{tabular}{|l|l|l|l|l|}
\hline Govista & Ano 9 & n. 20 & Outubro - Novembro 2020 & p. $188-208$ \\
\hline
\end{tabular}


Depois de todas as apresentações realizadas, o professor lançava uma crítica construtiva aos grupos tendo em vista a necessidade de apontar onde os discentes podiam melhorar suas exposições no momento de suas explicações sobre os referidos temas.

Essa avaliação tinha como objetivo fazer com que os estudantes exercitassem a criação de perguntas filosóficas, expusessem suas compreensões dos conteúdos e conceitos, apresentassem as questões construídas e fizessem uma crítica a aspectos de nossa cultura que não nos permite pensar filosoficamente, porém que fosse representado de maneira criativa.

A mudança na dinâmica de avaliação permitiu observar que a metodologia pode ser aplicada seguindo os passos em sua devida sequência e que ela pode ainda funcionar com outros modos de avaliação. O Quadro 1 , a seguir, demonstra os dados referentes à avaliação realizada pelos estudantes da aplicação da metodologia nas aulas de filosofia.

\begin{tabular}{|l|c|c|}
\hline \multicolumn{1}{|c|}{ QUADRO 1 - DA METODOLOGIA APLICADA NAS AULAS } \\
\hline \multicolumn{1}{|c|}{ PERGUNTAS } & SIM & NÃO \\
\hline \multicolumn{1}{|c|}{ M metodologia é interessante? } & 21 & 0 \\
\hline \multicolumn{1}{|c|}{ Metodologia e aprendizagem } & 8 & 0 \\
\hline $\begin{array}{l}\text { Você achou importante a forma como foram trabalhados os conteúdos de } \\
\text { filosofia? }\end{array}$ & 21 & 0 \\
\hline \multicolumn{1}{|c|}{ Metogia e aplicação de conteúdos } & FACILITA & DIFICULTA \\
\hline A metodologia dificulta ou facilita a aprendizagem? & SIM \\
\hline $\begin{array}{l}\text { a) A metodologia aplicada junto aos conteúdos de filosofia lhe fez pensar de } \\
\text { maneira crítica-reflexiva e facilitou a sua interpretação de textos e conceitos } \\
\text { filosóficos? Por quê? }\end{array}$ & 21 & 0 \\
\hline $\begin{array}{l}\text { b) A metodologia aplicada junto aos conteúdos de filosofia melhorou a sua } \\
\text { prática argumentativa e lhe fez pensar de maneira diferenciada, filosófica? Por } \\
\text { quê? }\end{array}$ & 20 & 1 \\
\hline $\begin{array}{l}\text { c) A metodologia aplicada junto aos conteúdos estudados de filosofia } \\
\text { possibilitou você perceber a sua relação com sua própria cultura do tempo } \\
\text { presente? Por quê? }\end{array}$ & 21 & \multirow{2}{*}{0} \\
\hline $\begin{array}{l}\text { d) A partir da metodologia aplicada e da compreensão dos conteúdos estudados } \\
\text { de filosofia, foi possível pensar de maneira diferenciada (filosófica) e } \\
\text { impulsionar seu pensamento a querer sempre se superar? Por quê? }\end{array}$ & 20 & 1 \\
\hline
\end{tabular}

Pode-se observar no Quadro 1 que, ao serem perguntados se a metodologia é interessante, todos os participantes responderam positivamente. Porém, quando questionados se a metodologia é cansativa, 13 alunos afirmaram não ser e 8 asseguraram ser cansativa. Logo, se se tomar como critério a escolha da maioria dos estudantes em evidenciar que a metodologia não é cansativa, pode-se inferir que ela é apenas em parte cansativa.

Com efeito, na pergunta feita em seguida, se os estudantes acharam importante a forma como foram trabalhados os conteúdos de filosofia, todos sem exceção asseguraram que "sim". Já na pergunta que leva em consideração a questão do aprendizado, ao serem

\begin{tabular}{|c|c|c|c|c|}
\hline Qevista Dialeatus & Ano 9 & n. 20 & Outubro - Novembro 2020 & p. $188-208$ \\
\hline
\end{tabular}


perguntados se a metodologia facilita ou dificulta o aprendizado, todos os estudantes unanimemente responderam afirmando que a metodologia facilita, portanto, a aprendizagem.

A partir do que se observa, pode-se afirmar que, embora a metodologia seja em parte cansativa, ela é interessante, facilita a aprendizagem e as estratégias utilizadas na aplicação dela são positivas, o que torna importante a forma de se trabalhar os conteúdos de filosofia.

Parte-se para a análise das perguntas do item que se refere à metodologia e aplicação de conteúdos. Com efeito, é importante afirmar que para a análise das respostas que implicam saber o "porquê" implícito nas questões, foram criados pelos autores dois pontos referenciais tendo em vista possibilitar a análise conclusiva das devidas respostas, a saber:

(1) Resposta esperada;

(2) Categoria de análise.

É importante destacar que os aspectos presentes nas respostas esperadas e as categorias de análise encontram-se presentes nas condições didáticas que fazem referência à construção da metodologia desenvolvida a partir da leitura que se faz dos apontamentos da filosofia de Nietzsche. Desse modo, vale ressaltar que tais condições didáticas da metodologia aplicada estão intimamente ligadas aos dois principais movimentos do pensamento nietzschiano, da genealogia e da autossuperação de si, que torna possível verificar a validade da metodologia desenvolvida.

Devido ao caráter sumário deste artigo, descrevem-se somente as análises relacionadas com as questões "c" e "d" do questionário. Partindo para a pergunta tal qual podese identificar na letra "c", é verificável no Quadro 1 que 21 alunos responderam de modo positivo que "sim". No que tange ao "porquê" que se faz presente na questão, esperava-se que os estudantes respondessem em conformidade com o seguinte:

Resposta esperada: porque a metodologia proporcionou perceber nossa cultura a partir dos conteúdos e fazer uma relação crítica com nossa cultura atual.

Categoria de análise 1: relação crítica cultural.

Os elementos semelhantes possíveis de serem verificados que se sobressaíram nessa questão foi que 13 alunos evidenciaram que conseguiram fazer uma relação com o passado e o presente, percebendo sua cultura fazendo ainda, críticas sobre a cultura atual. Contudo, 8 alunos disseram que conseguiram fazer uma relação do conteúdo estudado com aspectos do cotidiano. Uma vez que unanimemente todos os estudantes responderam positivamente à questão e que a maior parte dos discentes afirmou ter uma relação crítica com sua cultura, e a menor parte ter

\begin{tabular}{|l|l|l|l|l|}
\hline Govista Qialectus & Ano 9 & n. 20 & Outubro - Novembro 2020 & p. 188 - 208 \\
\hline
\end{tabular}


conseguido relacionar os conteúdos estudados com o cotidiano, pela junção dos elementos presentes nas respostas dos educandos tendo por base a resposta esperada e a categoria de análise 1, pode-se inferir que a metodologia aplicada junto aos conteúdos estudados de filosofia possibilitou aos estudantes compreenderem sua própria cultura do tempo presente, criticamente.

$\mathrm{Na}$ questão identificada pela letra "d", verifica-se que 20 alunos responderam positivamente que "sim" e apenas um respondeu que "não". No que diz respeito ao "porquê" da pergunta, esperava-se que os discentes respondessem de acordo com o seguinte:

Resposta esperada: porque a metodologia facilitou compreender os conteúdos de filosofia, pensar de modo filosófico sobre a realidade e nos direcionou a querer se superar.

Categoria de análise 2: pensar filosófico e superação.

Levando em consideração os elementos semelhantes possíveis de serem encontrados que sobressaíram nas respostas, verificou-se que pelo menos 15 alunos evidenciaram que a aplicação da metodologia fez com que entendessem os conteúdos, pensassem filosoficamente os assuntos e a realidade de forma crítica e os ajudou a praticar a autossuperação. Porém, outros cinco estudantes afirmaram em suas respostas que a metodologia os fizera querer se superar, e um dos educandos ao responder "não" à questão, chegou a evidenciar não ser possível alcançar de modo algum o que estava posto na pergunta. Assim, tomando como critério a junção dos elementos respondidos pela maioria dos alunos tendo por base a resposta esperada e a categoria de análise 2, tendo em vista que 15 dos estudantes enfatizaram o pensar filosófico e a superação, e pelo menos cinco afirmaram querer se superar, pode-se inferir que a partir da metodologia aplicada e da compreensão dos conteúdos estudados de filosofia foi possível aos estudantes pensarem filosoficamente, o que os impulsionou a quererem se superar.

Por fim, a última questão presente no questionário a ser analisada constitui-se como uma pergunta de caráter propriamente chave uma vez que ela toca justamente no aspecto principal do qual os estudantes fazem de maneira geral: uma autoavaliação de sua aprendizagem. A pergunta apresenta-se da seguinte maneira, a saber: como você avalia sua aprendizagem depois da aplicação da metodologia nas aulas de filosofia? Nas respostas, observou-se que 13 dos estudantes responderam positivamente qualificando sua aprendizagem como muito satisfatória após a aplicação da metodologia e outros 8 alunos responderam de modo positivo considerando sua aprendizagem como satisfatória. Assim, uma vez que todos os educandos a partir de suas percepções e respostas avaliaram de maneira positiva os itens "muito 
satisfatória" e "satisfatória", pode-se inferir de maneira conclusiva que a metodologia fez com que os estudantes aprendessem de modo significativo os conteúdos de filosofia.

Diante do que foi exposto a partir dos dados e análises que foram feitas sobre o questionário, é possível identificar que a metodologia aplicada nas aulas de filosofia na $2^{\mathrm{a}}$ série do ensino médio proporcionou aos estudantes facilidade na construção de crítica filosófica e interpretação de textos e conceitos filosóficos. Além disso, possibilitou aos discentes a melhoria da prática argumentativa e pensar filosoficamente sobre os conteúdos e a realidade cotidiana dos mesmos. Ainda, a partir da compreensão dos conteúdos de filosofia propiciou aos educandos perceber sua cultura e ter uma relação crítica com a cultura atualmente presente. Outrossim, a metodologia facilitou os estudantes compreenderem os conteúdos da disciplina pensando filosoficamente a realidade direcionando-os a querer se superar. Além do mais, segundo a concepção dos discentes utilizando o critério da escolha da maioria, pode-se identificar e concluir que a aplicação da metodologia nas aulas de filosofia produziu uma aprendizagem muito satisfatória. Portanto, tendo em vista que todos os objetivos foram alcançados na aplicação da metodologia e que os aspectos discutidos da mesma encontram-se de acordo com os movimentos do pensamento nietzschiano, da genealogia e da autossuperação de si, que é também critério que torna possível verificar a validade da metodologia aplicada nas aulas de filosofia, chega-se à conclusão da validação da mesma para o ensino de filosofia levando em consideração a análise do questionário.

Assim, que procuremos como docentes de filosofia cada vez mais aprimorar nossas práticas, para assim, fazer com que nossas aulas tornem-se um ambiente de aprendizagens de conteúdos e conceitos filosóficos, de interpretação e experiência da investigação de problemas, da pergunta e da crítica filosófica, da produção de filosofia como criação autêntica da atividade do pensar autônomo, que seja proporcionada uma aula que possa, por assim dizer, ser vivenciada na prática a experiência filosófica em um ambiente de ensino filosófico.

Além do questionário, a roda de conversa também foi utilizada para avaliar a atividade com os estudantes, visando reunir as opiniões dos alunos participantes da pesquisa (gravada em áudio) acerca de como eles avaliam o processo de execução do projeto de pesquisa, como também oferecer-lhes a oportunidade de apresentar de modo avaliativo suas opiniões dos aspectos que se referem à metodologia aplicada em sala de aula e situações de aprendizagem dos alunos na disciplina de filosofia. Assim, apresentam-se a seguir os relatos e análise de algumas das falas dos estudantes da $2^{\mathrm{a}}$ série do ensino médio.

\section{4}


O que se expressa nos relatos dos estudantes e o que interessa para análise neste artigo é a possibilidade de observar nas falas dos discentes o movimento nietzschiano da autossuperação de si, uma vez que a superação de si se expressa quando assim afirma Nietzsche (2011, p. 110): "E este segredo a própria vida me contou. "Vê", disse, eu sou aquilo que sempre tem de superar a si mesmo". Noutras palavras, o que se pretende primordialmente como critério avaliativo é saber se os educandos conseguiram atingir quatro objetivos: pensar filosoficamente; compreender os conteúdos de filosofia; produzir filosofia e se superar.

Seguindo o roteiro de questões proposto na roda de conversa avaliativa, os discentes foram perguntados: como vocês avaliam o processo de execução do projeto de pesquisa? A aluna "A" afirmou que "é uma excelente metodologia, bem estruturada e bastante adaptada ao nível do ensino médio e que ajudou para acrescentar na bagagem de estudos". Foi perguntado se a discente podia dizer quais foram os pontos que fez com que essa metodologia contribuísse na bagagem de estudos e compreensão dos conteúdos, ao que ela respondeu afirmando: "principalmente as redações filosóficas ajudaram na questão da argumentação e nas redações da disciplina de produção de texto como também no diálogo (discurso) e na forma de pensar de maneira ampliada". Pode-se identificar que alguns aspectos foram enfatizados de maneira positiva: a metodologia tida como excelente e bem estruturada; ajudou na argumentação e nas redações da disciplina de produção de texto bem como no desenvolver do discurso e forma de pensar, isso significa dizer que os discentes conseguiram pensar filosoficamente.

Em seguida, foi questionado aos estudantes como eles qualificavam sua forma de pensar depois das execuções metodológicas e após eles terem criado as perguntas filosóficas, se poderiam identificar na metodologia aplicada algum ponto que a partir da compreensão dos conteúdos de filosofia conseguiam olhar de modo diferenciado para as questões da realidade nos dias atuais, a aluna "B" afirmou que "a metodologia em sua aplicação nos fez pensar de maneira crítica e diferente do pensar massificado". O aluno "C" expressou que concordava com sua colega, dizendo que "a metodologia nos fez compreender as teorias e pensar além delas", o mesmo exemplificou que "as redações e os trabalhos nos ajudaram não só no campo da filosofia, mas em várias outras áreas como no campo de produção de texto". Chegou ainda a afirmar que "os trabalhos e os assuntos de modo geral nos fez pensar de forma mais crítica. Ora, o pensar de maneira crítica faz parte do pensar filosófico, com efeito, os alunos compreenderam os conteúdos teóricos e, ainda, a metodologia os ajudou a produzir redação filosófica como também chegou a ajudá-los nas redações da disciplina de produção de texto e

\section{5}


nas outras áreas do conhecimento, mantendo uma dinâmica interdisciplinar, e, ainda, os fizeram pensar de forma crítica.

\section{Considerações finais}

Considera-se que a metodologia de avaliação dos resultados da pesquisa-ação é fundamental para que o professor pesquisador, também sujeito participante na ação da pesquisa, compreenda que sua observação é elemento indispensável para compor o campo avaliativo sobre os resultados.

Ora, o pesquisador como participante nas ações da pesquisa, adquire outros conhecimentos que servem como subsídio para o cumprimento de sua análise reflexiva sobre a realidade vivenciada e isso conduz à reflexão sobre sua prática, o que implica, necessariamente, modificações em seu conhecimento.

Nas etapas de execuções metodológicas nas aulas, foi possível identificar avanços no desenvolvimento do pensamento filosófico dos discentes, os quais se envolveram na investigação dos temas propostos a partir dos textos de filosofia presentes no livro didático estudado, fazendo análise interpretativa e levantamento de questões sobre os assuntos, o que veio a dar suporte para compreenderem os conteúdos e em seguida construir as próprias perguntas filosóficas. Isso, a princípio, mostrou-se como uma tarefa difícil visto que os estudantes não tinham o hábito de criar questões críticas relacionando os conteúdos estudados com os aspectos do cotidiano de sua cultura atual. Baseando-se nas ideias e concepções dos autores da filosofia, vivenciaram na prática a atividade de construção de crítica filosófica direcionando-as a fatos sociais reais engajando-se na proposta nietzschiana da crítica da cultura, apontando os elementos encontrados na sociedade atual que impactam e influenciam no modo de ser dos indivíduos e influenciam na identidade destes em sua cultura e impedem a autossuperação do ser humano.

Em relação às avaliações de verificação de aprendizagem dos estudantes, pode-se afirmar que eles se sobressaíram de maneira positiva nas apresentações de trabalho criativo, vivenciando na prática a tarefa de investigar e interpretar textos e concepções filosóficas, compreender os assuntos e conceitos filosóficos, criar questões filosóficas e socializá-las diante da turma, assim como apresentar de maneira explicativa os temas propostos em forma de seminário no qual ao fim do trabalho lançavam uma crítica à presente realidade cultural por meio de poesia, desenho, mapa mental, entre outros. Com essas apresentações, também

\begin{tabular}{|c|c|c|c|c|}
\hline Qevista Dialeatus & Ano 9 & n. 20 & Outubro - Novembro 2020 & p. $188-208$ \\
\hline
\end{tabular}


puderam produzir filosofia e expressarem-se filosoficamente e posicionarem-se criticamente de modo criativo sobre os problemas metafísicos relacionados à cultura presente.

No que se refere à aprendizagem, foi perceptível que os estudantes compreenderam conceitos filosóficos que norteiam o tema da metafísica da antiguidade à modernidade bem como as concepções da crítica fillosófica nietzschiana (contemporânea), uma vez que demonstraram clareza e segurança nas explicações dos conceitos, tanto nas apresentações de trabalhos como na escrita das redações evidenciando conhecimento do contexto histórico dos filósofos em suas épocas, o que tornou óbvia a aprendizagem discente sobre os conteúdos de filosofia que foram trabalhados nas aulas.

Diante da experiência de todo o processo vivenciado no decorrer da pesquisa, cabe dizer que as ações metodológicas nas aulas, em constante interação com os estudantes, possibilitaram o desenvolvimento dos alunos à medida que se cumpria cada etapa, reforçando, assim, que o êxito de uma aprendizagem filosófica depende de um trabalho filosófico consistente que esteja focado em tratar com seriedade de todos os aspectos que levam em consideração o processo ensino-aprendizagem. A pesquisa possibilita ainda contribuir para a compreensão da complexidade do vasto campo que permeia o tema do ensino da filosofia.

Outrossim, é importante afirmar que não se pode concluir que a metodologia adotada possa ser aplicada a quaisquer conteúdos de filosofia haja vista que a pesquisa concentrou a aplicação no tema da metafísica, logo, não houve a possibilidade de colocá-la em prática com outros conteúdos, o que limitou testá-la nos mais diversos temas da filosofia.

Em suma, a pesquisa contribuiu significativamente pois trouxe à tona $o$ cumprimento do que se tinha como objetivo: criar uma metodologia filosófica para o ensino da filosofia no ensino médio em diálogo com o pensamento de Nietzsche.

\section{Referências}

DIAS, Rosa Maria. Nietzsche, vida como obra de arte. Org. Evandro Nascimento. Rio de Janeiro-RJ: Civilização Brasileira, 2011.

FOUCAULT, Michel. Dits et Écrits I - 1954-1969. Paris: Gallimard, 1994.

LARROSA, Jorge (Org.). Nietzsche e a Educação. 3. ed. Tradução Semíramis Gorini da Veiga. Belo Horizonte: Autêntica, 2009.

NIETZSCHE, Friedrich Wilhelm. Genealogia da moral: uma polêmica. Tradução e notas de Paulo César de Souza. São Paulo: Companhia das Letras, 1998.

\begin{tabular}{|c|c|c|c|c|}
\hline Qovista Dialectus & Ano 9 & n. 20 & Outubro - Novembro 2020 & p. $188-208$ \\
\hline
\end{tabular}


NIETZSCHE, Friedrich Wilhelm. A gaia ciência. Tradução: Paulo César de Souza. São Paulo: Companhia das Letras, 2001.

NIETZSCHE, Friedrich Wilhelm. Escritos sobre educação: Friedrich Nietzsche. Tradução, apresentação e notas de Noéli Correia de Melo Sobrinho. Rio de Janeiro: Ed. PUC-Rio; São Paulo: Loyola, 2003.

NIETZSCHE, Friedrich Wilhelm. Sobre o Futuro dos Nossos Estabelecimentos de Ensino. In: NIETZSCHE, Friedrich Wilhelm. Escritos sobre educação: Friedrich Nietzsche. Tradução, apresentação e notas de Noéli Correia de Melo Sobrinho. Rio de Janeiro: Ed. PUC-Rio; São Paulo: Loyola, 2003, p. 41-137.

NIETZSCHE, Friedrich Wilhelm. III Consideração Intempestiva: Schopenhauer Educador. In: NIETZSCHE, Friedrich Wilhelm. Escritos sobre educação: Friedrich Nietzsche. Tradução, apresentação e notas de Noéli Correia de Melo Sobrinho. Rio de Janeiro: Ed. PUCRio; São Paulo: Loyola, 2003, p. 138-222.

SOARES JÚNIOR, Antônio Batista. Nietzsche e o ensino de filosofia: uma metodologia para o ensino médio. Dissertação (Mestrado Profissional em Filosofia) - Universidade do Estado do Rio Grande do Norte, 2019.

THIOLLENT, Michel. Metodologia da pesquisa-ação. São Paulo: Cortez, 2008.

YIN, Robert K. Pesquisa qualitativa do início ao fim. Porto Alegre: Penso, 2016.

\begin{tabular}{|l|l|l|l|l|}
\hline Qevista 2 Dialectus & Ano 9 & n. 20 & Outubro - Novembro 2020 & p. $188-208$ \\
\hline
\end{tabular}

